\title{
An Empirical Analysis of the Elderly's Participation in Community Education
}

\author{
Xianghong Ju \\ Zhejiang Radio and Television University, Hangzhou, China \\ Email: 724250799@qq.com
}

How to cite this paper: Ju, X.H. (2020) An Empirical Analysis of the Elderly's Participation in Community Education. Open Access Library Journal, 7: e6246.

https://doi.org/10.4236/oalib.1106246

Received: March 19, 2020

Accepted: April 24, 2020

Published: April 27, 2020

Copyright $\odot 2020$ by author(s) and Open Access Library Inc.

This work is licensed under the Creative Commons Attribution International License (CC BY 4.0).

http://creativecommons.org/licenses/by/4.0/

\begin{abstract}
Population aging is a global trend. In the 1990s, China began to step into an aging society. Education for the aged is one of the components of education for all and is also the last stage of lifelong education. Based on the investigation and analysis of the elderly's participation in community education in $\mathrm{HZ}$ City, this paper understands the basic situation of the elderly's participation in community education, and puts forward some suggestions and strategies to better promote the development of community education.
\end{abstract}

\section{Subject Areas \\ Education, Sociology}

\section{Keywords}

The Elderly, Community Education, Empirical Analysis

\section{Introduction}

With the advent of aging population, the world has gradually entered an aging society, which has become a global trend. Aging is caused by the decrease of fertility rate and the extension of life expectancy, which leads to the unreasonable total population structure, mainly reflected in the decrease of the young population and the increase of the old population. Aging usually contains two meanings: one is the relative increase of the elderly population; the other is the aging state of the social population structure [1]. According to the relevant data provided by UN World Population Prospects 2008, from a global perspective, in the next 40 years (2010-2050), the scale and proportion of the world's aging population will increase rapidly. The population over 60 years old will grow from 760 million to 2 billion, and the proportion of the total population will rise from $11 \%$ to $22 \%$. In the 1990 s, China began to step into an aging society, and the trend is 
more and more obvious [2]. Mencius once said: Expand the respect of the aged in one's family to that of other families; expand the love of the young ones in one's family to that of other families. Care for the elderly and elderly education is an obligatory task. In the National Outline for Medium and Long Term Education Reform and Development (2010-2020), it is also clearly proposed to attach importance to the education for the elderly and build a lifelong education system. In order to deeply understand the situation of the elderly's participation in community education and actively carry out the elderly education, this paper takes the elderly in HZ City as the object of investigation. Through investigation and data collection, it makes an empirical analysis on the basic situation of the elderly's participation in the community education, so as to provide decisionmaking reference for the targeted organization of the elderly community education and the promotion of the construction of a learning society.

\section{Description Statistics on the Respondents}

In this survey, the elderly in HZ City are taken as the objects. The elderly here refer to those who are over 60 years old and under 80 years old after retirement. 250 questionnaires were randomly distributed and 250 valid questionnaires were recovered. The statistical software SPSS19 was used for analysis. In terms of reliability and validity analysis, the coefficient of Cronbach $\alpha$ in the survey data is 0.65 , indicating that the reliability of the questionnaire is within the acceptable range. In terms of validity, the content design of the questionnaire is consistent with the research topic, which has the theoretical basis and is recognized by relevant experts in practical operation. As shown in Table 1, among the respondents, $43.2 \%$ were men and $56.8 \%$ were women. $25 \%$ were aged $60-64,36.4 \%$ were aged $65-69,27.3 \%$ were aged $70-74,6.8 \%$ were aged $75-79$ and $4.5 \%$ were aged over 80 . From the perspective of age, 60 - 70 years old is the main group of participants, and the number of people over 80 years old is very small, only some of the elderly with relatively strong body participate.

In terms of education level (as shown in Table 2), illiteracy accounted for $2.3 \%$, primary school for $4.5 \%$, junior high school for $20.5 \%$, high school or technical secondary school for $50 \%$, junior college and above for $22.7 \%$. Among the respondents, people with high school or technical secondary school education are the main groups participating in community education.

In terms of occupations engaged by the elderly before retirement, as shown in Table 3, administrative units accounted for $18.2 \%$, public institutions $31.8 \%$, enterprises $36.4 \%$, farmers $2.3 \%$, self-employed $2.3 \%$, unemployed and others $9.1 \%$. The old people who used to work in enterprises and institutions accounted for the majority, while the old people who retired from the existing work units accounted for the majority.

In terms of monthly income (as shown in Table 4), 11.4\% were below 1000 RMB, $11.4 \%$ were 1000 - $2000 \mathrm{RMB}, 22.7 \%$ were 2000 - $3000 \mathrm{RMB}, 18.2 \%$ were $3000-4000 \mathrm{RMB}$, and $36.4 \%$ were above $4000 \mathrm{RMB}$. From the perspective of income, the number of the elderly with a monthly income of more than 3000 
RMB is relatively large, which is also in line with the situation of HZ City, and closely related to their work unit, educational background and professional title.

Table 1. Age.

\begin{tabular}{cccc}
\hline & Frequency & Percentage & Cumulative percentage \\
\hline $60-64$ years old & 55 & 25.0 & 25.0 \\
$65-69$ years old & 80 & 36.4 & 61.4 \\
$70-74$ years old & 60 & 27.3 & 88.7 \\
$75-79$ years old & 15 & 6.8 & 95.5 \\
80 years old and above & 10 & 4.5 & 100.0 \\
In total & 220 & 100.0 & \\
\hline
\end{tabular}

Table 2. Education level.

\begin{tabular}{cccc}
\hline & Frequency & Percentage & Cumulative percentage \\
\hline Illiteracy & 5 & 2.3 & 2.3 \\
Primary school & 10 & 4.5 & 6.8 \\
Junior high school & 45 & 20.5 & 27.3 \\
High school or technical secondary school & 110 & 50.0 & 77.3 \\
Junior college and above & 50 & 22.7 & 100.0 \\
In total & 220 & 100.0 & \\
\hline
\end{tabular}

Table 3. Occupations before retirement.

\begin{tabular}{cccc}
\hline & Frequency & Percentage & Cumulative percentage \\
\hline Administrative units & 40 & 18.1 & 18.1 \\
Public institutions & 70 & 31.8 & 49.9 \\
Enterprises & 80 & 36.4 & 86.3 \\
Farmers & 5 & 2.3 & 88.6 \\
Self-employed & 5 & 2.3 & 90.9 \\
Unemployed & 5 & 2.3 & 93.2 \\
Others & 15 & 6.8 & 100.0 \\
In total & 220 & 100.0 & \\
\hline
\end{tabular}

Table 4. Monthly income.

\begin{tabular}{cccc}
\hline & Frequency & Percentage & Cumulative percentage \\
\hline Below 1000 RMB & 25 & 11.4 & 11.4 \\
$1000-$ 2000 RMB & 25 & 11.4 & 22.8 \\
$2000-3000 \mathrm{RMB}$ & 50 & 22.7 & 45.5 \\
$3000-4000 \mathrm{RMB}$ & 40 & 18.2 & 63.7 \\
Above 4000 RMB & 80 & 36.3 & 100.0 \\
In total & 220 & 100.0 & \\
\hline
\end{tabular}




\section{An Empirical Analysis of Participation in Community Education}

\subsection{Support Condition for Participation in Community Education}

The participation of the elderly in community education can not be separated from the support of the family. This paper makes an investigation from three aspects: living conditions, taking care of grandchildren, children's support and so on [3].

\subsubsection{Current Living Conditions}

The survey of current living conditions mainly focuses on the living conditions of the elderly at the present stage, which is related to whether they have a stable foothold for participating in community education. The following options were set up: living with the married partner, living with children and the married partner, living independently and others. As shown in Table 5, living with the married partner accounts for the vast majority, about $47.7 \%$. According to the statistics provided by the Health and Family Planning Commission of HZ City, the life expectancy of the registered population of HZ City in 2014 was 81.56 years old, an increase of 0.58 over the 80.98 years old in 2013 . The life expectancy of men and women in HZ City is 79.57 and 83.70 respectively. As for the elderly living with the married partner, the increase of free time and the extension of life span provide the possibility for participating in community education activities.

\subsubsection{Taking Care of Grandchildren}

In cities and towns, it is very common for parents to help taking care of grandchildren. On the one hand, the elderly are willing to spend more time with their grandchildren. On the other hand, the elderly's children are busy with work and are under great pressure. Some of them live far away from the work place and it's difficult for them to take care of their own children without the help from an elderly family member or a nanny. Therefore, the elderly's help in taking care of their grandchildren can relieve the great pressure on their children. As shown in Table 6, 59.1\% of the respondents provided the help in taking care of their grandchildren for a long time or occasionally, and $40.9 \%$ of them did not take care of grandchildren, which is in line with the current situation. The longer the elderly take care of grandchildren, the less time they spend in community education, and the fewer times they participate in community education, or even do not participate in it.

\subsubsection{Whether Children Support}

After retirement, some elderly people will feel a sense of loss when they stop their busy work. Meanwhile, some elderly people feel lonely because their partners are not around or have passed away. In order to help parents get out of this emotion, their children are very supportive of their participation in community education or other elderly activities. According to the survey (as shown in Table 
7), $88.6 \%$ of the elderly confirmed that their children support them to participate in the elderly community education activities, and only a few do not support them.

\subsection{Basic Situation of Participating in Community Education}

In the investigation of the basic situation of participating in community education, it mainly analyzes the relevant factors from three aspects: learning environment, cost expenditure and teaching content.

\subsubsection{Purpose of Participating in Community Education}

There are many learning purposes for the elderly to participate in community education, such as interest, health, time and emotional communication, etc., and multiple choice questions are set here (as shown in Table 8). In data processing, the normalization method is used. In this survey, it is found that the majority of the elderly choose to meet their hobbies, increase health care knowledge and communicate with others, indicating that most of elderly pay more attention to their interests, health and emotional communication after retirement, which is also the main purpose of their participation in community education [4].

Table 5. Current living conditions.

\begin{tabular}{cccc}
\hline & Frequency & Percentage & Cumulative percentage \\
\hline Living with the married partner & 105 & 47.7 & 47.7 \\
Living with children and the married partner & 70 & 31.8 & 79.5 \\
Living independently & 35 & 15.9 & 95.5 \\
Others & 10 & 4.5 & 100.0 \\
In total & 220 & 100.0 & \\
\hline
\end{tabular}

Table 6. Taking care of grandchildren.

\begin{tabular}{cccc}
\hline & Frequency & Percentage & Cumulative percentage \\
\hline Always & 75 & 34.1 & 34.1 \\
No & 90 & 40.9 & 75.0 \\
Occasionally & 55 & 25.0 & 100.0 \\
In total & 220 & 100.0 & \\
\hline
\end{tabular}

Table 7. Whether children support.

\begin{tabular}{cccc}
\hline & Frequency & Percentage & Cumulative percentage \\
\hline Yes & 195 & 88.6 & 88.6 \\
No & 5 & 2.3 & 90.9 \\
It doesn't matter. & 20 & 9.1 & 100.0 \\
In total & 220 & 100.0 & \\
\hline
\end{tabular}


Table 8. Purpose of participating in community education.

\begin{tabular}{ccc}
\hline & Frequency & Percentage \\
\hline Meet hobbies & 180 & 27.27 \\
Increase health care knowledge & 185 & 28.03 \\
Improve cultural level & 75 & 11.37 \\
Communicate with others & 160 & 24.24 \\
Kill time & 40 & 6.06 \\
Re-employment & 15 & 2.27 \\
Others & 5 & 0.76 \\
In total & 660 & 100 \\
\hline
\end{tabular}

\subsubsection{Learning Distance}

To some extent, the distance of learning will affect the enthusiasm of the elderly to participate, because if the distance is far, the probability of safety risk may be high. In the survey (as shown in Table 9), within $1 \mathrm{~km}$ is the most acceptable distance for the elderly, which is convenient for them to go back and forth, and can also take care of the family, especially take care of the grandchildren.

\subsubsection{Opportunities to Participate in Learning}

In the survey of the learning opportunities for the elderly to participate in community education, it is found that there are still many opportunities for the elderly to participate in community education in urban areas, especially in big cities, while there are relatively few opportunities in rural areas, and there are few or no opportunities in some remote places (as shown in Table 10). The reasons are as follows: first, the financial support of big cities is large, and the government has invested a lot in community education; second, there are more resources available for education, such as health preservation, interest and hobby classes; third, the elderly in cities do not often work in the fields like the rural elderly, they have more leisure time, and the time to participate in community education is more guaranteed.

\subsubsection{Course Fee Standard}

Many of the courses in community education are free, but some may charge a small fee. When investigating the charging standard of a single course, we found that the lower the fee, the more popular it is. As shown in Table 11, free courses are the most popular. According to the purpose of the previous survey, it mainly comes from three aspects: hobbies, health and emotional communication. Therefore, if the cost of a single course is low, the enthusiasm of participation will be higher.

\subsubsection{Willingness to Pay}

As shown in Table 12, in the case of willing support for education every year, $200 \mathrm{RMB}$ is the most, and $500 \mathrm{RMB}$ is a boundary, which is closely related to the 
previous fee standard for single course. If the single course charges a higher fee, the elderly may be willing to pay a higher fee. In addition, most courses provided by community education in $\mathrm{HZ}$ city are free, so there is not a lot of support in this survey.

Table 9. Learning distance.

\begin{tabular}{cccc}
\hline & Frequency & Percentage & Cumulative percentage \\
\hline Within $1 \mathrm{~km}$ & 140 & 63.6 & 63.6 \\
$1-2 \mathrm{~km}$ & 15 & 6.8 & 70.5 \\
$3-4 \mathrm{~km}$ & 45 & 20.5 & 90.9 \\
$5 \mathrm{~km}$ and above & 20 & 9.1 & 100.0 \\
In total & 220 & 100.0 & \\
\hline
\end{tabular}

Table 10. Opportunities to participate in learning.

\begin{tabular}{cccc}
\hline & Frequency & Percentage & Cumulative percentage \\
\hline A lot & 105 & 47.7 & 47.7 \\
Many & 55 & 25.0 & 72.7 \\
Relatively few & 55 & 25.0 & 97.7 \\
Few or no & 5 & 2.3 & 100.0 \\
In total & 220 & 100.0 & \\
\hline
\end{tabular}

Table 11. Fed standard for single course.

\begin{tabular}{cccc}
\hline & Frequency & Percentage & Cumulative percentage \\
\hline Free & 90 & 40.9 & 40.9 \\
Below 50 RMB & 60 & 27.3 & 68.2 \\
$50-100 \mathrm{RMB}$ & 55 & 25.0 & 93.2 \\
$100-150 \mathrm{RMB}$ & 10 & 4.5 & 97.7 \\
Above 150 RMB & 5 & 2.3 & 100.0 \\
In total & 220 & 100.0 & \\
\hline
\end{tabular}

Table 12. Willingness to pay.

\begin{tabular}{cccc}
\hline & Frequency & Percentage & Cumulative percentage \\
\hline Free & 55 & 25.0 & 25.0 \\
Below 200 RMB & 90 & 40.9 & 65.9 \\
$200-500 \mathrm{RMB}$ & 55 & 25.0 & 90.9 \\
$500-1000 \mathrm{RMB}$ & 15 & 6.8 & 97.7 \\
Above $1000 \mathrm{RMB}$ & 5 & 2.3 & 100.0 \\
In total & 220 & 100.0 & \\
\hline
\end{tabular}




\subsubsection{Teaching Content}

Teaching content is also a consideration factor for the elderly to participate in community education. If the teaching content is attractive and meets their needs, the enthusiasm of participation will be higher. Otherwise, the enthusiasm of participation will be greatly reduced. It is found in the survey (as shown in Table 13) that the majority (77.3\%) of the respondents are satisfied with the teaching content, which is suitable and meets the needs of the elderly [5].

\subsubsection{Teachers}

The quality level of teachers will directly affect the development of community education, and also affect the attraction of community education to the participants. Many elderly students prefer to follow famous teachers. If the teachers go to another place to have classes, a lot of elderly students may go together with them. In the survey (as shown in Table 14), it is found that there are rich and high-quality teachers in community education in HZ City, accounting for about $50 \%$ of this option. The lack of teachers is very few, which is closely related to the level of education development in big cities.

\subsection{Learning Evaluation}

\subsubsection{Importance}

The national outline of education development plan clearly states that to develop lifelong education. Community education, as one of the ideal ways to build a lifelong education system, has been recognized by people and will still play a huge potential in the future. In the survey (as shown in Table 15), the absolute majority (95.5\%) of the respondents believe that community education is of great significance, which shows that the elderly have fully realized and have experienced the positive impact of community education on them. In addition, community education has certain continuity, social adaptability and means diversity, which make it play an irreplaceable role in the lifelong education system [6].

\subsubsection{Satisfaction}

Investigating the satisfaction can help us to understand the current situation of the elderly's participation in community education, to see whether the current community education meets their needs, to provide impetus for improving community education, and to promote the innovation and development of community education. It is found in the survey (as shown in Table 16) that most of the respondents are very satisfied with participating in community education and have no dissatisfied attitude towards community education. The survey result also shows that the efforts of HZ City in promoting community education are recognized and satisfied by the elderly.

\subsubsection{Help for the Health of the Elderly}

In recent years, the aging of the population has gradually become an international trend and problem. With the increase of the elderly population, the physical and mental health of the elderly has also been concerned by all sectors of society. After retirement, the elderly will pay more attention to their own health 
problems. The health mentioned here includes physical and mental health. They often go to some health lectures, learn some health knowledge, and buy some health products. In the survey (as shown in Table 17), most (95.5\%) of the respondents think it is helpful to participate in community education for their own health. On one hand, the elderly can learn some health knowledge through participating in community education. On the other hand, the elderly can also communicate with others in the process of community education, which is beneficial to their mental health [7].

Table 13. Teaching content.

\begin{tabular}{cccc}
\hline & Frequency & Effective Percentage & Cumulative percentage \\
\hline Lack of variety & 15 & 6.8 & 6.8 \\
Not up-to-date & 5 & 2.3 & 9.1 \\
Divorced from reality & 5 & 2.3 & 11.4 \\
Not meet the needs & 10 & 4.5 & 15.9 \\
Very good & 170 & 77.3 & 93.2 \\
Others & 15 & 6.8 & 100.0 \\
In total & 220 & 100.0 & \\
\hline
\end{tabular}

Table 14. Teachers.

\begin{tabular}{cccc}
\hline & Frequency & Percentage & Cumulative percentage \\
\hline Rich and high-quality & 110 & 50.0 & 50.0 \\
Not rich but high-quality & 40 & 18.2 & 68.2 \\
A few and general-quality & 55 & 25.0 & 93.2 \\
Lack of & 5 & 2.3 & 95.5 \\
Others & 10 & 4.5 & 100.0 \\
In total & 220 & 100.0 & \\
\hline
\end{tabular}

Table 15. Importance of participating in community education.

\begin{tabular}{cccc}
\hline & Frequency & Percentage & Cumulative percentage \\
\hline Important & 210 & 95.5 & 95.5 \\
Ordinary & 5 & 2.3 & 97.7 \\
Unimportant & 5 & 2.3 & 100.0 \\
In total & 220 & 100.0 & \\
\hline
\end{tabular}

Table 16. Satisfaction with participation in community education.

\begin{tabular}{cccc}
\hline & Frequency & Percentage & Cumulative percentage \\
\hline Very satisfied & 100 & 45.5 & 45.5 \\
Satisfied & 50 & 22.7 & 68.2 \\
Ordinary & 35 & 15.9 & 84.1 \\
Dissatisfied & 35 & 15.9 & 100.0 \\
Very dissatisfied & 0 & 0 & 100.0 \\
In total & 220 & 100.0 & \\
\hline
\end{tabular}


Table 17. Help for the health of the elderly.

\begin{tabular}{cccc}
\hline & Frequency & Percentage & Cumulative percentage \\
\hline Helpful & 210 & 95.5 & 100.0 \\
No help & 10 & 4.5 & 4.5 \\
In total & 220 & 100.0 & \\
\hline
\end{tabular}

\subsubsection{Help for the Support for the Aged}

One of the functions of community education is to meet the needs of elderly education activities in the community. From this perspective, community education has a certain role in the support for the aged. In the survey (as shown in Table 18), 86.4\% of the respondents said that community education was helpful for the support for the aged, while a small number of them held a negative attitude. It also reflects that the community education in some areas (such as Shangcheng District, Xiacheng District, Xihu District, Gongshu District, etc.) of HZ City is well done, which is closely related to the government's attention and strong support.

\subsubsection{Help for Family Harmony}

As shown in Table 19, 90.9\% of the respondents agreed that participating in community education is helpful for family harmony. It is also found that many children are afraid that their old parents will feel lonely, especially if one of their parents has passed away. Most of these children hope that their parents can go out more and contact with the outside world more, which will be helpful for family harmony and can reduce some conflicts at home.

\subsection{Problems in Community Education}

\subsubsection{Views on Teaching}

According to the result of investigating respondents' views on teaching, some problems in community education should be paid more attention to. Many of the respondents were satisfied with the teaching form, but think there are still some improvements in teaching content, participation and learning habits of the elderly. As shown in Table 20.

\subsubsection{Dissatisfaction with Community Education}

The survey on the dissatisfaction of community education is set up with multiple choices, so normalized data processing is adopted. As shown in Table 21, the respondents were most dissatisfied with the poor teaching quality, followed by "Too far away from home" and "Unreasonable curriculum arrangement". It shows that the elderly pay high attention to teaching-related factors. If there are problems in teaching, it will directly affect their satisfaction evaluation.

\subsubsection{What Needs to Be Improved in Community Education}

The survey on what needs to be improved in community education is set up with multiple choices, so normalized data processing is adopted. As shown in Table 
22, not many respondents think that the content, form, cost and teachers in community education need to be improved. More of them think the education facilities need to be improved. Generally speaking, the community education facilities in $\mathrm{HZ}$ city meet the basic needs, but better community education facilities will be more beneficial for the elderly to participate in community education activities.

Table 18. Help for the support for the aged.

\begin{tabular}{cccc}
\hline & Frequency & Percentage & Cumulative percentage \\
\hline Helpful & 190 & 86.4 & 100.0 \\
No help & 30 & 13.6 & 13.6 \\
In total & 220 & 100.0 & \\
\hline
\end{tabular}

Table 19. Help for family harmony.

\begin{tabular}{cccc}
\hline & Frequency & Percentage & Cumulative percentage \\
\hline Helpful & 200 & 90.9 & 100.0 \\
No help & 20 & 9.1 & 9.1 \\
In total & 220 & 100.0 \\
\hline
\end{tabular}

Table 20. Views on teaching.

\begin{tabular}{cccc}
\hline & Frequency & Percentage & Cumulative percentage \\
\hline $\begin{array}{c}\text { Monotony of teaching content } \\
\text { Not in line with the }\end{array}$ & 10 & 4.5 & 4.5 \\
elderly's learning habits & 20 & 9.0 & 13.6 \\
Poor participation & 25 & 11.3 & 25.0 \\
Satisfied with the teaching form & 135 & 61.1 & 86.4 \\
Others & 30 & 13.6 & 100.0 \\
In total & 220 & 99.5 & \\
\hline
\end{tabular}

Table 21. Dissatisfaction with community education.

\begin{tabular}{ccc}
\hline & Frequency & Percentage \\
\hline Unreasonable curriculum arrangement & 30 & 10.9 \\
Overcharge & 20 & 7.3 \\
Unreasonable time arrangement & 10 & 3.6 \\
Too far away from home & 40 & 14.5 \\
Management problem & 15 & 5.5 \\
Logistics support issues & 20 & 7.3 \\
Learning environment problems & 20 & 7.3 \\
Teaching quality problems & 120 & 43.6 \\
In total & 275 & 100.0 \\
\hline
\end{tabular}


Table 22. What needs to be improved in community education.

\begin{tabular}{ccc}
\hline & Frequency & Percentage \\
\hline Education content & 65 & 14.6 \\
Education form & 80 & 17.9 \\
Education facilities & 100 & 22.5 \\
Education cost & 75 & 16.9 \\
Teachers & 65 & 14.6 \\
Others & 60 & 13.5 \\
In total & 445 & 100.0 \\
\hline
\end{tabular}

\section{Conclusions and Discussion}

\subsection{Conclusions}

First, this study shows that community education for the elderly is very popular. Most of the elderly are highly satisfied with participating in community education. The enthusiasm of the elderly to participate in community education is strong, and the number of participants is relatively large. In particular, some courses related to the elderly's hobbies or beneficial to the physical and mental health of the elderly, and some well-known teachers' lectures are often full of people. To meet the educational psychological needs of the elderly, some communities often carry out a variety of community education and cultural activities.

Secondly, family support is crucial for the elderly to participate in community education. As an important part of the family, it is very important if the elderly can get the support of their family members when they participate in community education. For the elderly in HZ City, most families support them to participate in community education. Some children of the elderly are very reasonable, and also hope that the elderly can go out more and participate in some community activities, which is very helpful for the elderly themselves and is of great help to family harmony.

Thirdly, the construction of teaching in community education for the elderly should be strengthened. The survey shows that the elderly pay more attention to teaching when they participate in community education. However, with the continuous development and expansion of community education, some teaching construction such as teaching content, teachers, teaching environment and facilities, can not keep up with the demand. Therefore, when carrying our community education for the elderly, it is necessary to provide and improve the relevant teaching construction, otherwise, it will become one of the key problems restricting the development of community education.

\subsection{Discussion}

\subsubsection{Multiple Support and Attention}

The development of community education for the aged can not be separated from the support of the government, the community and the residents. Since the 
16th National Congress of the Communist Party of China was held, great emphasis has given to building a well-off society of "learning for all, learning for life, and promoting the all-round development of people", and taking community education as an important carrier and link of building life-long education. The development of community education for the elderly is a system involving lot of resources such as funds, venues, teachers and environment. To run a good community education for the elderly, the elements of these resources are indispensable, and they should form a joint force, so as to build an effective community education to meet the needs of the elderly.

\subsubsection{Paying Attention to the Balance of Community Education for the Elderly}

In some community education places for the elderly in HZ City, the enrollments have increased a lot. For some projects paid by the government, it is too difficult to be enrolled for the elderly. However, in some other community education places, the elderly can easily choose the community education projects according to their own needs. In fact, there are also differences in the balance of the development of community education in different regions. Some communities have good conditions and large investment, where the site facilities can meet the needs of the development of community education for the elderly, but some regions have relatively poor development. In addition, the regional and urban-rural gap in community education should be paid more attention as well.

\subsubsection{Constructing High-Quality Teaching Resources}

The construction of community education resources for the elderly is a very important part of the development of community education system for the elderly. However, the quantity and quality of community education resources for the elderly need to be further improved, especially increasing investment in the construction of high-quality teaching resources that are lacking. On the basis of the construction of these high-quality resources, the standards for the construction of educational resources for the elderly should be established at the same time. This standard can be used as a reference to standardize the construction of other resources, so as to improve the overall quality and level of resource construction [8].

\section{Acknowledgements}

This paper is the stage research result of 2015 planning project "Theoretical and Practical Exploration of Community Elderly Education from the Perspective of Lifelong Education: A Case Study of Zhejiang Province" (No. ZMYB201509) of Department of Civil Affairs of Zhejiang Province, and is supported by 312 Talent Training Project of Zhejiang Radio and Television University.

\section{Conflicts of Interest}

The author declares no conflicts of interest regarding the publication of this paper. 


\section{References}

[1] Population Aging. https://baike.so.com/doc/206568-218477.html

[2] Ye, Z.H. (2013) Some Basic Theoretical Issues of Elderly Education. Modern Distance Education Research, No. 6, 11-16.

[3] Wang, C. and Yao, H. (2016) Investigation and Reflection on the Needs of Community Elderly Education. Journal of Shaanxi Youth Vocational College, No. 2, 67-73.

[4] Health Experts (2013) What Is the Purpose of Foreign Universities for the Elderly? https://www.cndzys.com/lnsh/51238.html

[5] Wei, L.Z. (2018) Analysis on the Construction of Community Elderly Education Curriculum from the Perspective of Population Aging. China Adult Education, No. 24, 112-114.

[6] Sun, Y.F. (2012) Practice and Exploration of Community Elderly Education. Elderly Education (University for the Elderly), No. 12, 55-56.

[7] Lu, J.J. (2015) Is the Third Age Education Not Ready? http://www.cssn.cn/jyx/jyx_zdtj/201512/t20151202_2737147.shtml

[8] Fang, X. (2013) Tianjin University for the Elderly to Expand the Coverage of Elderly Education-Quality Education Resources to the Community.

http://roll.sohu.com/20131013/n388062415.shtml 